\title{
The immunology of traumatic brain injury: a prime target for Alzheimer's disease prevention
}

\author{
Brian Giunta ${ }^{1,2,3,5^{*}}$, Demian Obregon ${ }^{1,4}$, Renuka Velisetty ${ }^{2}$, Paul R Sanberg ${ }^{3}$, Cesar V Borlongan ${ }^{3}$ and Jun Tan Ta, $^{1,4}$
}

\begin{abstract}
A global health problem, traumatic brain injury (TBI) is especially prevalent in the current era of ongoing world military conflicts. Its pathological hallmark is one or more primary injury foci, followed by a spread to initially normal brain areas via cascades of inflammatory cytokines and chemokines resulting in an amplification of the original tissue injury by microglia and other central nervous system immune cells. In some cases this may predispose individuals to later development of Alzheimer's disease (AD). The inflammatory-based progression of TBI has been shown to be active in humans for up to 17 years post TBI. Unfortunately, all neuroprotective drug trials have failed, and specific treatments remain less than efficacious. These poor results might be explained by too much of a scientific focus on neurons without addressing the functions of microglia in the brain, which are at the center of proinflammatory cytokine generation. To address this issue, we provide a survey of the TBI-related brain immunological mechanisms that may promote progression to AD. We discuss these immune and microglia-based inflammatory mechanisms involved in the progression of post-trauma brain damage to AD. Flavonoid-based strategies to oppose the antigen-presenting cell-like inflammatory phenotype of microglia will also be reviewed. The goal is to provide a rationale for investigations of inflammatory response following TBI which may represent a pathological link to AD. In the end, a better understanding of neuroinflammation could open therapeutic avenues for abrogation of secondary cell death and behavioral symptoms that may mediate the progression of TBI to later AD.
\end{abstract}

Keywords: traumatic brain injury, flavonoids, microglia phenotype, Alzheimer's disease, cytokines

\section{Epidemiology of post-traumatic brain injury Alzheimer's disease}

It has been suggested that a long-term process of amyloid-beta $(\mathrm{A} \beta)$ metabolism is initiated by traumatic brain injury (TBI). Chronic axonal pathology seems to supply all of the needed machinery for both the anabolism and catabolism of $A \beta$ [1]. These $A \beta$ plaques formed in the initial weeks after injury may actually regress with time. In this case, a continuously renewed store of $A \beta$ in degenerating axons can be kept in check through degradation by endogenous mediators such as neprilysin or adequate numbers of anti-inflammatory phagocytic microglia [1]. In a subset of TBI patients, the balance between $A \beta$ anabolism and catabolism eventually shifts

\footnotetext{
* Correspondence: bgiunta@health.usf.edu

'James A. Haley Veterans' Administration Hospital, 13000 Bruce B. Downs Blvd., Tampa, FL 33612, USA

${ }^{2}$ Department of Psychiatry and Behavioral Neurosciences, Neuroimmunology Laboratory, Morsani College of Medicine, University of South Florida, 3515 E. Fletcher Ave., Tampa, FL 33613, USA

Full list of author information is available at the end of the article
}

during the aging process, accounting for the epidemiologic evidence of a link between TBI and Alzheimer's disease (AD) [1]. A deficiency in microglial clearance of $A \beta$ could possibly account for this balance shift since aging microglia are known to have a reduced phagocytic capacity and this is observed in AD [2]; the most common age-related dementia. Indeed, in 2006 there were 26.6 million people with $\mathrm{AD}$ worldwide, and this number is predicted to quadruple by the year 2050 [3]. As such, an understanding of the mechanisms promoting $\mathrm{AD}$ risk is important. A history of TBI is a strong risk factor for $\mathrm{AD}$ [3-11], although there remains an incomplete consensus since some epidemiological studies have not uncovered such an association [12-18]. This is probably due to the retrospective nature of some studies that may have led to recall bias (systematic error due to inaccuracies in subjects' ability to recall their history of TBI). This can be a confounding source especially when collecting data from patients regarding their cognitive impairments or from secondary informants [19]. Indeed, 
larger, more controlled studies, including level 1 evidence (which requires prospective examination and randomization) [20], have led to an overall acceptance that TBI is a risk factor for AD development [15].

Although TBI is typically believed to be a static pathological insult from a single event, new clinical unrecognized clinical symptoms can arise many years after the initial injury. Indeed, patients may display alterations in their daily living activities long after TBI and may develop $\mathrm{AD}$ [21].

Along these lines, there is evidence that a history of TBI accelerates the AD onset to younger ages [22-24] and that the more severe the injury, the greater the risk of developing AD [20,25]. Repetitive mild TBI especially promotes incapacitating consequences and AD-like cognitive deficits are reported in such cases. For example, in a study of 2,552 retired professional American football players there was a five-fold increase in the precursor to $\mathrm{AD}$, mild cognitive impairment, and a threefold increase of reported significant memory problems among retirees with three or more reported concussions compared with retirees with no history of concussion [26]. This study also detected an earlier onset of AD in the retirees compared with the general American male population.

In other human studies, TBI has been shown to result in amyloid deposits reminiscent of $\mathrm{AD}$ pathology [27,28]. The first piece of evidence to suggest a mechanistic correlation between $\mathrm{TBI}$ and $\mathrm{AD}$ was the observation that $\mathrm{A} \beta$ plaques are found in up to $30 \%$ of patients who die acutely post TBI [27]. The senile plaques were found in all age groups, even children. Conversely, in control cases (patients who died from non-neurological causes), these plaques were detected almost exclusively in older individuals [27]. Additionally, plaques have even been observed in tissue surrounding contusions that was surgically removed from survivors of TBI [29]. Moreover, the neuritic plaques in TBI patients are very similar to those in the early stages of $\mathrm{AD}$ [19]. The major difference is that $\mathrm{AD}$ plaques develop slowly and are largely found in older people, whereas TBIassociated plaques can appear rapidly (within just a few hours) after injury [27]. The predominant form of $A \beta$ in the plaques formed after TBI, and in the soluble $A \beta$ found in the brains of these patients, is $A \beta_{42}$ - which, as mentioned earlier, is prone to aggregate.

As TBI is a complex and heterogeneous syndrome, the type and severity of the acute inflammatory pathology probably has a central role in determining the risk of developing AD. Moreover, the baseline susceptibility or mental reserve of the patient may be predetermined by multiple factors including age, sex, and the interaction of several known or unknown genetic factors [19].

In the brains of patients suffering chronic TBI, several neuropathological hallmarks of AD (in addition to amyloid) have been noted - including neurofibrillary tangles, acetylcholine deficiency, and tau immunoreactivity [30]. A common feature of these pathologies is that they initiate and potentiate a brain inflammatory cascade that we hypothesize as the central mechanistic link between TBI and later development of $\mathrm{AD}$.

\section{Inflammation links traumatic brain injury to later Alzheimer's disease development}

The initial inflammatory response of TBI $[8,11,21]$ may be key to later $\mathrm{AD}$ development. This response results in neuronal injury and often in disruption of the bloodbrain barrier. Microglial cells react to this injury within minutes, and stay activated chronically [31]. Once induced into this state, the microglia become nearly identical to peripheral macrophages, acting as antigenpresenting cells (APC) and secreting proinflammatory cytokines and chemokines [32,33]. For a full review of the activation states of microglia see Town and colleagues [34]. In animal models - including, but not limited to, fluid-percussion brain injury in rats [11], and combined unilateral lesion of the arm area of the primary motor cortex and arm area of the lateral premotor cortex in rhesus monkeys $[21,35]$ - it was found that the initial inflammatory response persists for at least 1 year, especially in the thalamus $[11,21,35]$.

In humans as well, postmortem studies have shown microglial activation many years after TBI [36]. Sites of activation often coincide with those of neuronal degeneration and axonal abnormality, and include disconnected nuclei such as the thalamus [8]. In humans, the positron emission tomography ligand ${ }^{3 \mathrm{H}} \mathrm{PK} 11195$ detects subacute microglial activation at the site of strokes, as well as in remote white matter connected to the lesion $[37,38]$. Later, thalamic and brainstem microglial activation becomes evident due to the disconnection of these areas. Autoradiographic studies in rat models of TBI demonstrate an increased thalamic uptake of ${ }^{3 \mathrm{H}} \mathrm{PK} 11195$ linked to a 31-fold increase in microglial numbers in the thalamus ipsilateral to a cortical injury. In a recent study of TBI patients using this modality, it was found that increased microglial activation can be present up to 17 years after TBI [36]. This observation indicates that TBI initiates a chronic inflammatory cycle and highlights the importance of considering the response to TBI as evolving over years or even decades [36].

As stated earlier, many of the pathologies of TBI [39] are mediated through an inflammatory cascade characterized by activation of microglia $[40,41]$ and through a concordant increase in proinflammatory cytokines [42,43]; both of which have the ability to exacerbate other pathologies including later dementia [44]. Microglia do not have simply one phenotypic manifestation [34]. As we have suggested previously, microglial cells exist in at least two functionally distinguishable states 
once activated - namely a phagocytic phenotype (innate activation) or the aforementioned antigen-presenting phenotype (adaptive activation) that is seen post TBI. When challenged with certain pathogen-associated molecular patterns (particularly CpG-DNA), murine microglia seem to activate a mixed response characterized by enhanced phagocytosis and proinflammatory cytokine production as well as adaptive activation of $\mathrm{T}$ cells. In the experimental autoimmune encephalitis model, murine microglia seem to largely support an adaptive activation of encephalitogenic $\mathrm{T}$ cells in the presence of the CD40-CD40 ligand interaction. In the context of $A \beta$ challenge, CD40 ligation is able to shift activated microglia from innate to adaptive activation; similar to the scenario post TBI. Further, it seems that the cytokine milieu to which microglia are exposed biases these cells to adaptive activation (that is, anti-inflammatory Th2associated cytokines such as IL-4, IL-10, and perhaps transforming growth factor-beta 1) or to an innate form of activation (that is, proinflammatory Th1-associated cytokines such as IFN $\gamma$, IL-6, and TNF $\alpha$ ) [34]. In this regard, innate activation of microglia generally leads to amyloidogenic amyloid precursor protein (APP) processing and the generation of $A \beta$ plaques [45-47]. Indeed, we have previously shown experimentally that blocking transforming growth factor- $\beta-\operatorname{Smad} 2 / 3$ innate immune signaling mitigates AD-like pathology [48].

Not all forms of microglial activation are deleterious, however, as activated microglia may serve a protective role in both TBI and AD. Regarding the former, at 3 hours post moderate fluid percussion in rats, the majority of new cells replacing the subventricular zone of the traumatized hemisphere were astrocytes, macrophage/microglia, oligodendrocytes, and neurons, with the majority of cells appearing glial in nature. These populations promoted neurogenesis in the granular cell layer of the hippocampus and suggest TBI stimulates widespread cellular proliferation for days after injury and results in focal neurogenesis in the dentate gyrus of the hippocampus promoted by microglia. These microglial responses to injury may therefore participate in brain repair and functional recovery [49].

Regarding the latter, it has been shown in $A \beta_{1-42^{-}}$ immunized mouse models of AD that microglial phagocytosis of $\beta$-amyloid plaques is at least partly responsible for the therapeutic benefit in these animals [34]. Since inflammation post TBI can last for many years, and since this inflammation is promoted by APC-like microglia, if we could repolarize these cells to their phagocytic state before the inflammation becomes chronic it may be prophylactic for post-TBI AD. Moreover, this also suggests interventions to stop the conversion of TBI to $A D$ may be beneficial for longer intervals after trauma than previously assumed [36].

\section{Intervention with natural flavonoids as a means of reducing the risk of Alzheimer's disease after traumatic brain injury}

The most common group of plant phenols, flavonoids are found in nuts, fruits, vegetables, grains, and tea. More than 6,000 different flavonoids have been described [50] and can be categorized into six classes by structure: flavonoles, flavones, isoflavones, flavanoles, flavanones, and anthocyanidins [51]. Flavonoids possess several physiological properties, including antioxidant, antibacterial, antiviral, antimutagenic, anticancer, and most importantly - anti-inflammatory properties $[52,53]$.

Flavonoids exist as glycoside and aglycone forms in plant-derived foods. After oral ingestion, flavonoids are extensively conjugated and metabolized during absorption in the small intestine and then again in the liver [54-56]. The intact form of flavonoid and the respective metabolites derived from flavonoid biotransformation in the gastrointestinal tract and in the liver are the forms that enter the circulation and ultimately reach the brain [57-59].

Several flavonoids have shown potential for the treatment of TBI symptoms in humans and animals. In this regard, Diamond and colleagues reviewed all researched conference proceedings and research papers identified in Medline, in the Research Council for Complementary Medicine database based on the British Library database, and in PsychInfo [60]. The review was extensive in that controlled clinical studies with both positive and negative findings were included, in addition to animal studies providing mechanisms of activity. The following are salient studies from this review [60].

Some $44 \%$ of TBI patients experience brain hypoxia, which can result in hypoperfusion and severe deficits of physical, psychological, and cognitive functions [61-68]. In a double-blind study of 50 patients suffering chronic cerebral insufficiency, patients were administered either $120 \mathrm{mg} /$ day Ginko Biloba extract (GBE) or placebo for 1 month prior to assessment [69]. Patients who received GBE showed improvements in motor activity, speech comprehension/production, and mood, as well as a reduction in dizziness [69]. Further, in a placebocontrolled, double-blind trial, GBE was administered at a dosage of $160 \mathrm{mg} /$ day for 6 weeks to 60 patients with cerebral insufficiency. Subjects from the GBE group were found to have had progressive improvement in concentration and reduction in fatigue. Between the second and fourth weeks of treatment, two-thirds of the patients on GBE showed improvement compared with one-fifth of the patients on placebo [69].

Moreover, in a double-blind, placebo-controlled study researching the effects of GBE on patients diagnosed with mild to moderate cerebrovascular insufficiency, 40 
outpatients receiving $120 \mathrm{mg} /$ day GBE for 12 weeks showed improvement on clinical assessment and on selfrating scales monitoring changes in dizziness, tinnitus, headaches, and hearing loss [70]. Eighteen out of 20 patients showed statistically significant improvements in tinnitus, dizziness, and in the frequency and severity of headaches [71]. Another study, involving 80 patients with cerebrovascular insufficiency, used a double-blind, placebocontrolled, crossover design to test the effects of GBE on perceptual reasoning [72]. Group A received GBE for the first 45 days and placebo for the remainder of the trial, and Group B initially received placebo followed by GBE. Patients in the GBE versus placebo treatment groups displayed significant improvement on the block design subtest of the Wechsler Adult Intelligence Scale [72] and on a visual-spatial construction task. It should be noted, however, that an improvement of 0.7 points on the block design subtest of the Wechsler Adult Intelligence Scale, while being statistically significant, is unlikely to represent a clinically meaningful change [72].

Le Bars and colleagues conducted a 52-week doubleblind, randomized placebo-controlled, multicenter clinical trial consisting of 309 patients with $\mathrm{AD}$ and multi-infarct dementia to study the efficacy and safety of EGb 761 (24\% ginkgo-flavone glycosides and 6\% terpenoids [73]). Patients were administered either EGb (120 mg/day) or placebo. Evaluable data were obtained from 202 of the original 309 patients at the 52-week end-point analysis. The cognitive subscale of the AD Assessment Scale, which was used to assess cognitive function in these patients, displayed positive changes in the patients who received EGb. Using the literature-based cutoff score of +4 as an indicator of change, $14 \%$ of the people in the placebo group displayed a positive change compared with $27 \%$ of the EGb treatment group [74]. The effect size appeared to be independent of age or severity of symptoms at baseline. When clinical symptom severity and treatment response were assessed, however, no differences were noted [74].

Overall, these findings suggest that ginkgo's broad spectrum of pharmacologic effects allows it to be used in the treatment of various neurologic functions (for example, cognitive, mood, motoric, headache, and motivational) that are associated with both $\mathrm{AD}$ and TBI (for example, cerebral insufficiency).

However, difficulties may still remain with brain bioavailability. This difficulty applies not so much with GBE but with other flavonoids, as will be expanded upon [60]. Several studies have been conducted to understand the pharmokinetics and pharmacodynamics of GBE. For example, expired radiolabeled ${ }^{i 4} \mathrm{C}-\mathrm{CO}_{2}$ extract was administered orally in a rat model, and it was found that $16 \%$ of the administered dose was excreted in the first 3 hours and a total of $38 \%$ after 72 hours. Twenty-one percent of the radiolabeled extract was excreted in the urine and 29\% was excreted in the feces [75]. Total absorption reached at least $60 \%$. Regarding the evaluation of blood-specific activity data, the pharmacokinetics of Ginko Biloba follow a two-compartment process. In the first-order phase, the biologic half-life is approximately 4.5 hours. In the second-order phase, the drug was distributed through plasma, followed by a gradual uptake after 48 hours [75]. The upper gastrointestinal tract was also an absorption site, as was neuronal, glandular, and ocular tissue [75].

In a study in which possible or probable $\mathrm{AD}$ patients received an oral dose of standardized extract of dry Ginko Biloba leaves, electroencephalogram changes within 3 hours showed that the extract was adequately absorbed, metabolized, and crossed the blood-brain barrier [76]. GBE, or its constituents, has exhibited halflives ranging from 2 to 4 hours while activity levels peak at 1.5 to 3 hours in animal and human models [60]. Regarding the mechanism of action of this flavonoid, GBE was shown to have activity both centrally and peripherally modulating electrochemical, physiologic, neurologic, and vascular systems in animals and humans with few adverse side effects or drug interactions. As such, GBE may show promise in patients with neurologic sequelae associated with both $\mathrm{AD}$ and TBI [60].

Green tea-derived epigallocatechin gallate (EGCG) has anti-amyloidogenic and anti-inflammatory properties in $\mathrm{AD}$ mouse models, but the comparable effective dose of EGCG in humans may exceed clinical convenience and/ or safety. We previously found that fish oil enhanced bioavailability of EGCG versus EGCG treatment alone $(P<0.001)$. Fish oil and EGCG therefore synergistically inhibit cerebral $\mathrm{A} \beta$ deposits $(P<0.001)$. This finding supports the use of fish oil supplementation with ECGC in order to have significant therapeutic potential for the treatment of AD or TBI [77].

One element of therapeutic animal studies is the type of simulated TBI: focal or diffuse. The majority of studies use a type of mechanical pneumatic or fluid percussion applied to the brain. It is common for both focal and diffuse damage to occur as the result of the same event; so for the purposes of this review we will treat both damage types the same in terms of $\mathrm{AD}$ risk. Further the literature does not differentiate diffuse versus focal in terms of $\mathrm{AD}$ risk [78]. For example, Di Giovanni and colleagues found that activation of cell cycle proteins after TBI is associated with cell death and caspase activation in neurons, but with proliferation of astrocytes and microglia [79]. This study was conducted over 17 days post injury in male Sprague-Dawley rats. Moreover, cell cycle inhibition by the flavonoid flavopiridol reduced neuron cell death and glial proliferation. Importantly, 
these changes were paralleled by a significant reduction in lesion volume and by nearly complete functional recovery [79]. In another study, rats were subjected to controlled cortical impact injury and then injected with the flavonoid baicalein $(30 \mathrm{mg} / \mathrm{kg})$ or vehicle immediately after injury or daily for 4 days. Improved functional recovery and reduced contusion volumes up to day 28 post injury were observed [80]. These changes were associated with significantly decreased levels, at the contusion site, of TNFa, IL$1 \beta$ and IL- 6 mRNA at 6 hours, and cytokine protein on day 1 post injury - suggesting that the neuroprotective effect of baicalein may be related to a decreased proinflammatory response following the injury [80].

In addition to our work on EGCG in AD mouse models, others found EGCG increased the number of surviving neuronal cells 1,3 , and 7 days post TBI (pneumatic-controlled injury device at 10 weeks of age) and provided an improvement in cerebral dysfunction in 6-week-old male Wistar rats. The authors suggest consumption of water containing EGCG pre and post TBI inhibits free radicalinduced neuronal degeneration and apoptotic cell death around the damaged area, resulting in the improvement of cerebral function following TBI [81]. Furthermore, we have found that EGCG promotes nonamyloidogenic processing of APP in mice, resulting in elevations of the neurotrophic soluble APP $\alpha$ [82]. Importantly, soluble APP $\alpha$ reduces neuronal injury and improves functional outcome following diffuse traumatic brain injury in rats $[83,84]$. In addition we have found that EGCG reduces APC-like microglia and re-polarizes them to phagocyticlike microglia [77,82,85-90].

We and others have also demonstrated that flavonoids significantly suppressed the activation of inflammatory pathways involved in TBI and $\mathrm{AD}$, including $\mathrm{NF}-\mathrm{kB}$ as well as mitogen-associated protein kinase pathways in activated microglia, resulting in an attenuation of the production of inflammatory molecules $[85,91,92]$. Luteolin, a flavonoid from celery and green peppers, was recently shown to suppress lipopolysaccharide (LPS)-induced IL-6 protein and mRNA expression by inhibiting activator protein-1 activation and phosphorylation of JNK in the murine microglial cell line BV-2 [91]. IL-6 is among the first cytokines upregulated post TBI [93]. Moreover, when mice were provided drinking water supplemented with luteolin before treatment with LPS, plasma IL-6 and IL-6 mRNA in the hippocampus were reduced compared with those not receiving luteolin [91]. In another study, luteolin affected the microglial transcriptome leading to an anti-inflammatory, anti-oxidative, and neuroprotective phenotype [94]. In further support we found that apigenin and luteolin also suppressed microglia TNF $\alpha$ and IL- 6 productions stimulated by IFN $\gamma$ in the presence of CD40 ligation [95].
In further support of the study by Di Giovanni and colleagues mentioned earlier [79], microglia are the major cells in the brain that generate inflammatory molecules including cytokines, superoxide, and nitric oxide. Previous studies reported that inhibition of these molecules is beneficial for mitigating neurodegenerative disorders [85] including TBI [79]. In the inflammatory response, NF- $\mathrm{kB}$ and activator protein-1 are important transcription factors, and mitogen-associated protein kinase (ERK1/2, p38 and JNK) pathways are involved in modulating inflammatory gene expression.

Furthermore, studies have shown that flavonoids exert neuroprotection through inhibiting microglia activation and the subsequent release of various inflammatory molecules. For example, pretreatment with luteolin attenuated inflammatory mediators (IL-1 $\beta$, TNF $\alpha$, nitric oxide, and prostaglandin E2) produced by LPS-stimulated microglia [96]. Supernatant from LPS-stimulated microglia caused discernible death in N2a cells (a neuroblastoma cell line). However, treating microglia with luteolin prior to LPS reduced neuronal cell death caused by conditioned supernatants [96]. Incubating N2a cells with luteolin did not protect them from supernatants from LPS-stimulated microglia, indicating that luteolin protects neurons by acting exclusively on microglia [96]. Zheng and colleagues also reported that the flavonoid fisetin decreased TNF $\alpha$ and nitric oxide production and significantly suppressed nuclear translocation of NF- $\mathrm{KB}$ and phosphorylation of p30 mitogen-associated protein kinase in the LPSstimulated BV-2 microglia cells [97]. In addition, fisetin reduced cytotoxicity of LPS-stimulated microglia toward B35 neuroblastoma cells in a co-culture system [97].

Inhibition of microglia by wogonin reduced cytotoxicity when co-cultured with pheochromocytoma PC12 cells, supporting a neuroprotective role for wogonin in vitro [98]. Other studies have shown that resveratrol, quercetin, or genistein diminished neuronal cell death induced by microglial activation $[99,100]$.

\section{Conclusions}

The inflammatory-based progression of brain injury has been shown to be active in humans for up to 17 years post-TBI. The proinflammatory, APC-like microglial phenotype is a common mechanistic link between both TBI and later development of AD. We and others have shown that naturally occurring flavonoids safely and effectively promote the neuroprotective, anti-inflammatory, phagocytic phenotype. Taken together, these results indicate that flavonoids may be important bioactives for attenuating microglia activation and neuronal cell damage by inflammatory conditions initially initiated by TBI. Ultimately, modulation of microglial phenotype with flavonoids or other compounds provides an avenue for abrogation of 
secondary cell death and behavioral symptoms that may mediate the progression of $\mathrm{TBI}$ and $\mathrm{AD}$.

\section{Abbreviations}

Aß: amyloid beta; AD: Alzheimer 's disease; APC: antigen-presenting cell; APP: amyloid precursor protein; EGCG: epigallocatechin gallate GBE, Ginko Biloba extract; IFN: interferon; IL: interleukin; JNK: c-Jun-N-terminal kinase; LPS: lipopolysaccharide; NF: nuclear factor; TBI: traumatic brain injury; Th: T-helper type; TNF: tumor necrosis factor.

\section{Competing interests}

PRS is a founder of NaturaTherapeutics, Inc., and has a consulting relationship but no employment with NaturaTherapeutics, Inc.; CVB is a consultant for NaturaTherapeutics, Inc. NT-020 is a patented formulation which includes flavonoids that is marketed by NaturaTherapeutics, Inc. The patent is held by PRS the University of South Florida and the Veterans Administration.

\section{Author details}

'James A. Haley Veterans' Administration Hospital, 13000 Bruce B. Downs Blvd., Tampa, FL 33612, USA. ${ }^{2}$ Department of Psychiatry and Behavioral Neurosciences, Neuroimmunology Laboratory, Morsani College of Medicine, University of South Florida, 3515 E. Fletcher Ave., Tampa, FL 33613, USA. ${ }^{3}$ Department of Neurosurgery and Brain Repair, Center of Excellence for Aging and Brain Repair, Morsani College of Medicine, University of South Florida, 12901 Bruce. B. Downs. Blvd., Tampa, FL 33612, USA. ${ }^{4}$ Department of Psychiatry and Behavioral Neurosciences, Silver Child Development Center, Rashid Laboratory for Developmental Neurobiology, Morsani College of Medicine, University of South Florida, 3515 E. Fletcher, Tampa, FL 33613, USA. ${ }^{5}$ Department of Psychiatry and Behavioral Neurosciences, University of South Florida, Morsani College of Medicine, 3515 E. Fletcher Avenue, Tampa, FL 33613, USA.

\section{Authors' contributions}

BG performed the background search and completed the first draft of the manuscript. DO conducted the literature search and assisted in the initial manuscript preparation. PRS and CVB contributed to the background material regarding which cytokines are promoted by TBI. BG and JT conceived the review subject. RV assisted with the response to the critique. All authors read and approved the final manuscript.

Received: 29 March 2012 Accepted: 09 July 2012

Published: 1 August 2012

\section{References}

1. Chen XH, Johnson VE, Uryu K, Trojanowski JQ, Smith DH: A lack of amyloid beta plaques despite persistent accumulation of amyloid beta in axons of long-term survivors of traumatic brain injury. Brain Pathol 2009, 19:214-223

2. Fiala M, Lin J, Ringman J, Kermani-Arab V, Tsao G, Patel A, Lossinsky AS, Graves MC, Gustavson A, Sayre J, Sofroni E, Suarez T, Chiappelli F, Bernard G: Ineffective phagocytosis of amyloid-beta by macrophages of Alzheimer's disease patients. J Alzheimers Dis 2005, 7:221-232. discussion 255-262.

3. Brookmeyer R, Johnson E, Ziegler-Graham K, Arrighi HM: Forecasting the global burden of Alzheimer's disease. Alzheimers Dement 2007, 3:186-191.

4. Fleminger $\mathrm{S}$, Oliver DL, Lovestone $\mathrm{S}$, Rabe-Hesketh $\mathrm{S}$, Giora A: Head injury as a risk factor for Alzheimer's disease: the evidence 10 years on; a partial replication. J Neurol Neurosurg Psychiatry 2003, 74:857-862

5. Geddes JF, Vowles GH, Nicoll JA, Revesz T: Neuronal cytoskeletal changes are an early consequence of repetitive head injury. Acta Neuropathol 1999, 98:171-178.

6. Gentleman SM, Leclercq PD, Moyes L, Graham DI, Smith C, Griffin WS, Nicoll JA: Long-term intracerebral inflammatory response after traumatic brain injury. Forensic Sci Int 2004, 146:97-104.

7. Kotapka MJ, Graham DI, Adams JH, Gennarelli TA: Hippocampal pathology in fatal non-missile human head injury. Acta Neuropathol 1992, 83: 530-534.

8. Maxwell WL, MacKinnon MA, Stewart JE, Graham DI: Stereology of cerebral cortex after traumatic brain injury matched to the Glasgow outcome score. Brain 2010, 133(Pt 1):139-160.
9. Nicoll JA, Mrak RE, Graham DI, Stewart J, Wilcock G, MacGowan S, Nicoll JA, Mrak RE, Graham DI, Stewart J, Wilcock G, MacGowan S, Esiri MM, Murray LS, Dewar D, Love S, Moss T, Griffin WS: Association of interleukin-1 gene polymorphisms with Alzheimer's disease. Ann Neurol 2000, 47:365-368.

10. Smith DH, Chen XH, Nonaka M, Trojanowski JQ, Lee VM, Saatman KE, Leoni MJ, Xu BN, Wolf JA, Meaney DF: Accumulation of amyloid beta and tau and the formation of neurofilament inclusions following diffuse brain injury in the pig. J Neuropathol Exp Neurol 1999, 58:982-992.

11. Smith DH, Chen XH, Pierce JE, Wolf JA, Trojanowski JQ, Graham DI, McIntosh TK: Progressive atrophy and neuron death for one year following brain trauma in the rat. I Neurotrauma 1997, 14:715-727.

12. Chandra V, Philipose V, Bell PA, Lazaroff A, Schoenberg BS: Case-control study of late onset 'probable Alzheimer's disease'. Neurology 1987 37:1295-1300.

13. Amaducci LA, Fratiglioni L, Rocca WA, Fieschi C, Livrea P, Pedone D, et al: Risk factors for clinically diagnosed Alzheimer's disease: a case-control study of an Italian population. Neurology 1986, 36:922-931.

14. Broe GA, Henderson AS, Creasey H, McCusker E, Korten AE, Jorm AF, Longley W, Anthony JC: A case-control study of Alzheimer's disease in Australia. Neurology 1990, 40:1698-1707.

15. Lye TC, Shores EA: Traumatic brain injury as a risk factor for Alzheimer's disease: a review. Neuropsychol Rev 2000, 10:115-129.

16. Katzman R, Aronson M, Fuld P, Kawas C, Brown T, Morgenstern H, Frishman W, Gidez L, Eder H, Ooi WL: Development of dementing illnesses in an 80-year-old volunteer cohort. Ann Neurol 1989, 25:317-324.

17. Williams DB, Annegers JF, Kokmen E, O'Brien PC, Kurland LT: Brain injury and neurologic sequelae: a cohort study of dementia, parkinsonism, and amyotrophic lateral sclerosis. Neurology 1991, 41:1554-1557.

18. Ferini-Strambi L, Smirne S, Garancini P, Pinto P, Franceschi M: Clinical and epidemiological aspects of Alzheimer's disease with presenile onset: a case control study. Neuroepidemiology 1990, 9:39-49.

19. Johnson VE, Stewart W, Smith DH: Traumatic brain injury and amyloid-beta pathology: a link to Alzheimer's disease? Nat Rev Neurosci 2010, 11:361-370.

20. Plassman BL, Havlik RJ, Steffens DC, Helms MJ, Newman TN, Drosdick D, Phillips C, Gau BA, Welsh-Bohmer KA, Burke JR, Guralnik JM, Breitner JC: Documented head injury in early adulthood and risk of Alzheimer's disease and other dementias. Neurology 2000, 55:1158-1166.

21. Nagamoto-Combs K, McNeal DW, Morecraft RJ, Combs CK: Prolonged microgliosis in the rhesus monkey central nervous system after traumatic brain injury. J Neurotrauma 2007, 24:1719-1742.

22. Schofield PW, Tang M, Marder K, Bell K, Dooneief G, Chun M, Sano M, Stern $Y$, Mayeux R: Alzheimer's disease after remote head injury: an incidence study. J Neurol Neurosurg Psychiatry 1997, 62:119-124.

23. Gedye A, Beattie BL, Tuokko H, Horton A, Korsarek E: Severe head injury hastens age of onset of Alzheimer's disease. J Am Geriatr Soc 1989, 37:970-973.

24. Nemetz PN, Leibson C, Naessens JM, Beard M, Kokmen E, Annegers JF, Kurland LT: Traumatic brain injury and time to onset of Alzheimer's disease: a population-based study. Am J Epidemiol 1999, 149:32-40.

25. Guo Z, Cupples LA, Kurz A, Auerbach SH, Volicer L, Chui H, Green RC, Sadovnick AD, Duara R, DeCarli C, Johnson K, Go RC, Growdon JH, Haines $J$, Kukull WA, Farrer LA: Head injury and the risk of AD in the MIRAGE study. Neurology 2000, 54:1316-1323.

26. Guskiewicz KM, Marshall SW, Bailes J, McCrea M, Cantu RC, Randolph C, Jordan BD: Association between recurrent concussion and late-life cognitive impairment in retired professional football players. Neurosurgery 2005, 57:719-726. discussion 719-726.

27. Roberts GW, Gentleman SM, Lynch A, Murray L, Landon M, Graham DI: Beta amyloid protein deposition in the brain after severe head injury: implications for the pathogenesis of Alzheimer's disease. J Neurol Neurosurg Psychiatry 1994, 57:419-425.

28. Ikonomovic MD, Uryu K, Abrahamson EE, Ciallella JR, Trojanowski JQ, Lee VM, Clark RS, Marion DW, Wisniewski SR, DeKosky ST: Alzheimer's pathology in human temporal cortex surgically excised after severe brain injury. Exp Neurol 2004, 190:192-203.

29. DeKosky ST, Abrahamson EE, Ciallella JR, Paljug WR, Wisniewski SR, Clark RS, Ikonomovic MD: Association of increased cortical soluble abeta42 levels with diffuse plaques after severe brain injury in humans. Arch Neurol 2007, 64:541-544.

30. Jordan BD: Chronic traumatic brain injury associated with boxing. Semin Neurol 2000, 20:179-185. 
31. Koshinaga M, Katayama Y, Fukushima M, Oshima H, Suma T, Takahata T: Rapid and widespread microglial activation induced by traumatic brain injury in rat brain slices. J Neurotrauma 2000, 17:185-192.

32. Gehrmann J, Banati RB, Wiessner C, Hossmann KA, Kreutzberg GW: Reactive microglia in cerebral ischaemia: an early mediator of tissue damage? Neuropathol Appl Neurobiol 1995, 21:277-289.

33. Gehrmann J, Matsumoto Y, Kreutzberg GW: Microglia: intrinsic immuneffector cell of the brain. Brain Res Brain Res Rev 1995, 20:269-287.

34. Town T, Nikolic V, Tan J: The microglial 'activation' continuum: from innate to adaptive responses. J Neuroinflammation 2005, 2:24.

35. Nagamoto-Combs K, Combs CK: Microglial phenotype is regulated by activity of the transcription factor, NFAT (nuclear factor of activated T cells). J Neurosci 2010, 30:9641-9646.

36. Ramlackhansingh AF, Brooks DJ, Greenwood RJ, Bose SK, Turkheimer FE, Kinnunen KM, Gentleman S, Heckemann RA, Gunanayagam K, Gelosa G, Sharp DJ: Inflammation after trauma: microglial activation and traumatic brain injury. Ann Neurol 2011, 70:374-383.

37. Thiel A, Radlinska BA, Paquette C, Sidel M, Soucy JP, Schirrmacher R, Minuk $\mathrm{J}$ : The temporal dynamics of poststroke neuroinflammation: a longitudinal diffusion tensor imaging-guided PET study with 11CPK11195 in acute subcortical stroke. J Nucl Med 2010, 51:1404-1412.

38. Gerhard A, Schwarz J, Myers R, Wise R, Banati RB: Evolution of microglial activation in patients after ischemic stroke: a [11C](R)-PK11195 PET study. Neurolmage 2005, 24:591-595.

39. Teasdale GM, Graham DI: Craniocerebral trauma: protection and retrieval of the neuronal population after injury. Neurosurgery 1998, 43:723-737. discussion 737-738.

40. Morganti-Kossmann MC, Satgunaseelan L, Bye N, Kossmann T: Modulation of immune response by head injury. Injury 2007, 38:1392-1400.

41. Carbonell WS, Grady MS: Regional and temporal characterization of neuronal, glial, and axonal response after traumatic brain injury in the mouse. Acta Neuropathol 1999, 98:396-406.

42. Dietrich WD, Chatzipanteli K, Vitarbo E, Wada K, Kinoshita K: The role of inflammatory processes in the pathophysiology and treatment of brain and spinal cord trauma. Acta Neurochir Suppl 2004, 89:69-74.

43. Morganti-Kossmann MC, Rancan M, Otto VI, Stahel PF, Kossmann T: Role of cerebral inflammation after traumatic brain injury: a revisited concept. Shock 2001, 16:165-177.

44. Zhang B, West EJ, Van KC, Gurkoff GG, Zhou J, Zhang XM, Kozikowski AP, Lyeth BG: HDAC inhibitor increases histone $\mathrm{H} 3$ acetylation and reduces microglia inflammatory response following traumatic brain injury in rats. Brain Res 2008, 1226:181-191.

45. Giunta B, Fernandez F, Nikolic WV, Obregon D, Rrapo E, Town T, Tan J: Inflammaging as a prodrome to Alzheimer's disease. I Neuroinflammation 2008, 5:51-62.

46. Blasko I, Stampfer-Kountchev M, Robatscher P, Veerhuis R, Eikelenboom P, Grubeck-Loebenstein B: How chronic inflammation can affect the brain and support the development of Alzheimer's disease in old age: the role of microglia and astrocytes. Aging Cell 2004, 3:169-176.

47. Marx F, Blasko I, Grubeck-Loebenstein B: Mechanisms of immune regulation in Alzheimer's disease: a viewpoint. Arch Immunol Ther Exp (Warsz) 1999, 47:205-209.

48. Town T, Laouar Y, Pittenger C, Mori T, Szekely CA, Tan J, Duman RS, Flavell RA: Blocking TGF-beta-Smad2/3 innate immune signaling mitigates Alzheimer-like pathology. Nat Med 2008, 14:681-687.

49. Urrea C, Castellanos DA, Sagen J, Tsoulfas P, Bramlett HM, Dietrich WD: Widespread cellular proliferation and focal neurogenesis after traumatic brain injury in the rat. Restor Neurol Neurosci 2007, 25:65-76.

50. Harborne JB, Williams CA: Advances in flavonoid research since 1992. Phytochemistry 2000, 55:481-504.

51. Jang S, Johnson RW: Can consuming flavonoids restore old microglia to their youthful state? Nutr Rev 2010, 68:719-728.

52. Rice-Evans C: Flavonoid antioxidants. Curr Med Chem 2001, 8:797-807.

53. Rice-Evans C: Flavonoids and isoflavones: absorption, metabolism, and bioactivity. Free Radic Biol Med 2004, 36:827-828.

54. Hollman PC, Katan MB: Absorption, metabolism and health effects of dietary flavonoids in man. Biomed Pharmacother 1997, 51:305-310.

55. Day AJ, Mellon F, Barron D, Sarrazin G, Morgan MR, Williamson G: Human metabolism of dietary flavonoids: identification of plasma metabolites of quercetin. Free Radic Res 2001, 35:941-952.
56. Natsume M, Osakabe N, Oyama M, Sasaki M, Baba S, Nakamura Y, Osawa T, Terao J: Structures of (-)-epicatechin glucuronide identified from plasma and urine after oral ingestion of (-)-epicatechin: differences between human and rat. Free Radic Biol Med 2003, 34:840-849.

57. Youdim KA, Qaiser MZ, Begley DJ, Rice-Evans CA, Abbott NJ: Flavonoid permeability across an in situ model of the blood-brain barrier. Free Radic Biol Med 2004, 36:592-604.

58. Peng HW, Cheng FC, Huang YT, Chen CF, Tsai T: Determination of naringenin and its glucuronide conjugate in rat plasma and brain tissue by high-performance liquid chromatography. J Chromatogr B: Biomed SCi Appl 1998, 714:369-374.

59. Peng HW, Huang YT, Chen CF, Tsai TH: Glucuronidation of naringenin in rats. Planta Med 1998, 64:779-790.

60. Diamond BJ, Shiflett SC, Feiwel N, Matheis RJ, Noskin O, Richards JA, Schoenberger NE: Ginkgo biloba extract: mechanisms and clinical indications. Arch Phys Med Rehabil 2000, 81:668-678.

61. Jeremitsky E, Omert L, Dunham CM, Protetch J, Rodriguez A: Harbingers of poor outcome the day after severe brain injury: hypothermia, hypoxia, and hypoperfusion. J Trauma 2003, 54:312-319.

62. Jones PA, Andrews PJ, Midgley S, Anderson SI, Piper IR, Tocher JL: Measuring the burden of secondary insults in head-injured patients during intensive care. J Neurosurg Anesthesiol 1994, 6:4-14.

63. McHugh GS, Engel DC, Butcher I, Steyerberg EW, Lu J, Mushkudiani N, Hernández AV, Marmarou A, Maas Al, Murray GD: Prognostic value of secondary insults in traumatic brain injury: results from the IMPACT study. J Neurotrauma 2007, 24:287-293.

64. Mushkudiani NA, Engel DC, Steyerberg EW, Butcher I, Lu J, Marmarou A, Slieker F, McHugh GS, Murray GD, Maas Al: Prognostic value of demographic characteristics in traumatic brain injury: results from the IMPACT study. J Neurotrauma 2007, 24:259-269.

65. Silverston P: Pulse oximetry at the roadside: a study of pulse oximetry in immediate care. BMJ 1989, 298:711-713.

66. Chesnut RM: Guidelines for the management of severe head injury: what we know and what we think we know. J Trauma 1997, 42(5 Suppl): S19-S22.

67. Newcombe VF, Williams GB, Scoffings D, Cross J, Carpenter TA, Pickard JD, Menon DK: Aetiological differences in neuroanatomy of the vegetative state: insights from diffusion tensor imaging and functional implications. J Neurol Neurosurg Psychiatry 2010, 81:552-561.

68. Adams JH, Graham DI, Murray LS, Scott G: Diffuse axonal injury due to nonmissile head injury in humans: an analysis of 45 cases. Ann Neurol 1982, 12:557-563.

69. Eckmann F, Schlag H: Controlled double-blind study for the determination of the effect of Tebonin forte in patients with cerebrovascular insufficiency. Fortschr Med 1982, 100:1474-1478.

70. Halama P: Ginkgo biloba: effectiveness of a special extract in patients with cerebral insufficiency. Munch Med Wochenschr 1991, 133:190-194.

71. Halama P, Bartsch G, Meng G: Disorders of brain performance of vascular origin. Randomized double-blind study of the effectiveness of Gingko biloba extract. Fortschr Med 1988, 106:408-412.

72. Arrigo CS, Weitbrecht WV: Clinical and Psychometric Evaluation of Ginkgo Biloba Extract in Chronic Cerebrovascular Diseases. London: John Libbey \& Company; 1985.

73. Chao JC, Chu CC: Effects of Ginkgo biloba extract on cell proliferation and cytotoxicity in human hepatocellular carcinoma cells. World $J$ Gastroenterol 2004, 10:37-41.

74. Le Bars KMM, Berman N, Le Bars KMM, Berman N, Itil TM, Freedman AM, Schatzberg AF: A placebo-controlled, double-blind, randomized trial of an extract of Ginkgo biloba for dementia. JAMA 1997, 278:1327-1332.

75. Moreau JP, Eck CR, McCabe J, Skinner S: Absorption, distribution and elimination of a labelled extract of Ginkgo biloba leaves in the rat. Presse Med 1986, 15:1458-1461

76. Itil T, Martorano D: Natural substances in psychiatry (Ginkgo biloba in dementia). Psychopharmacol Bull 1995, 31:147-158.

77. Giunta B, Hou H, Zhu Y, Salemi J, Ruscin A, Shytle RD, Tan J: Fish oil enhances anti-amyloidogenic properties of green tea EGCG in Tg2576 mice. Neurosci Lett 2010, 471:134-138.

78. Lovell MK FM: Neuropsychiatry of Traumatic Brain Injury. Neuropsychological assessment. Washington, DC: American Psychiatric Press; 1994:152-153.

79. Di Giovanni S, Movsesyan V, Ahmed F, Cernak I, Schinelli S, Stoica B, Faden Al: Cell cycle inhibition provides neuroprotection and reduces glial 
proliferation and scar formation after traumatic brain injury. Proc Natl Acad Sci U S A 2005, 102:8333-8338.

80. Chen SF, Hsu CW, Huang WH, Wang JY: Post-injury baicalein improves histological and functional outcomes and reduces inflammatory cytokines after experimental traumatic brain injury. Br J Pharmacol 2008, 155:1279-1296.

81. Itoh T, Imano M, Nishida S, Tsubaki M, Hashimoto S, Ito A, Satou T: (-)-Epigallocatechin-3-gallate protects against neuronal cell death and improves cerebral function after traumatic brain injury in rats. Neuromol Med 2011, 13:300-309.

82. Fernandez JW, Rezai-Zadeh K, Obregon D, Tan J: EGCG functions through estrogen receptor-mediated activation of ADAM10 in the promotion of non-amyloidogenic processing of APP. FEBS Lett 2011, 584:4259-4267.

83. Corrigan F, Pham CL, Vink R, Blumbergs PC, Masters $\mathrm{CL}$, van den Heuvel $\mathrm{C}$, Cappai $\mathrm{R}$ : The neuroprotective domains of the amyloid precursor protein, in traumatic brain injury, are located in the two growth factor domains. Brain Res 2011, 1378:137-143.

84. Thornton E, Vink R, Blumbergs PC, Van Den Heuvel C: Soluble amyloid precursor protein alpha reduces neuronal injury and improves functional outcome following diffuse traumatic brain injury in rats. Brain Res 2006, 1094:38-46.

85. Giunta B, Obregon D, Hou H, Zeng J, Sun N, Nikolic V, Ehrhart J, Shytle D, Fernandez F, Tan J: EGCG mitigates neurotoxicity mediated by HIV-1 proteins gp120 and Tat in the presence of IFN-gamma: role of JAK/ STAT1 signaling and implications for HIV-associated dementia. Brain Res 2006, 1123:216-225.

86. Giunta B, Zhou Y, Hou H, Rrapo E, Fernandez F, Tan J: HIV-1 TAT inhibits microglial phagocytosis of Abeta peptide. Int I Clin Exp Pathol 2008, 1:260-275.

87. Rrapo E, Zhu Y, Tian J, Hou H, Smith A, Fernandez F, Tan J, Giunta B: Green tea-EGCG reduces GFAP associated neuronal loss in HIV-1 Tat transgenic mice. Am J Transl Res 2009, 1:72-79.

88. Rezai-Zadeh $\mathrm{K}$, Arendash GW, Hou H, Fernandez F, Jensen M, Runfeldt M Shytle RD, Tan J: Green tea epigallocatechin-3-gallate (EGCG) reduces beta-amyloid mediated cognitive impairment and modulates tau pathology in Alzheimer transgenic mice. Brain Res 2008, 1214:177-187.

89. Obregon DF, Rezai-Zadeh K, Bai Y, Sun N, Hou H, Ehrhart J, Zeng J, Mori T, Arendash GW, Shytle D, Town T, Tan J: ADAM10 activation is required for green tea (-)-epigallocatechin-3-gallate-induced alpha-secretase cleavage of amyloid precursor protein. J Biol Chem 2006, 281:16419-16427.

90. Rezai-Zadeh K, Shytle D, Sun N, Mori T, Hou H, Jeanniton D, Ehrhart J, Townsend K, Zeng J, Morgan D, Hardy J, Town T, Tan J: Green tea epigallocatechin-3-gallate (EGCG) modulates amyloid precursor protein cleavage and reduces cerebral amyloidosis in Alzheimer transgenic mice. J Neurosci 2005, 25:8807-8814.

91. Jang SW, Lee JW, Park SH, Kim JH, Yoo M, Na DH, Lee KC: Gastroretentive drug delivery system of DA-6034, a new flavonoid derivative, for the treatment of gastritis. Int J Pharm 2008, 356:88-94.

92. Chen X, Yin OQ, Zuo Z, Chow MS: Pharmacokinetics and modeling of quercetin and metabolites. Pharm Res 2005, 22:892-901.

93. Ley EJ, Clond MA, Singer MB, Shouhed D, Salim A: IL6 deficiency affects function after traumatic brain injury. J Surg Res 2011, 170:253-256.

94. Dirscherl K, Karlstetter M, Ebert S, Kraus D, Hlawatsch J, Walczak Y, Moehle C, Fuchshofer R, Langmann $T$ : Luteolin triggers global changes in the microglial transcriptome leading to a unique anti-inflammatory and neuroprotective phenotype. J Neuroinflamm 2010, 7:3-16.

95. Kavon R-Z, Jared E, Yun B, Sanberg PR, Paula B, Jun T, Douglas Shytle R: Apigenin and luteolin modulate microglial activation via inhibition of STAT1-induced CD40 expression. J Neuroinflamm 2008, 5:41.

96. Jang S, Dilger RN, Johnson RW: Luteolin inhibits microglia and alters hippocampal-dependent spatial working memory in aged mice. J Nutr 2010, 140:1892-1898.

97. Zheng LT, Ock J, Kwon BM, Suk K: Suppressive effects of flavonoid fisetin on lipopolysaccharide-induced microglial activation and neurotoxicity. Int Immunopharmacol 2008, 8:484-494.

98. Lee H, Kim YO, Kim H, Kim SY, Noh HS, Kang SS, Cho GJ, Choi WS, Suk K: Flavonoid wogonin from medicinal herb is neuroprotective by inhibiting inflammatory activation of microglia. FASEB J 2003, 17:1943-1944.

99. Wang X, Chen S, Ma G, Ye M, Lu G: Genistein protects dopaminergic neurons by inhibiting microglial activation. Neuroreport 2005, 16:267-270.
100. Bureau G, Longpre F, Martinoli MG: Resveratrol and quercetin, two natural polyphenols, reduce apoptotic neuronal cell death induced by neuroinflammation. J Neurosci Res 2008, 86:403-410.

doi:10.1186/1742-2094-9-185

Cite this article as: Giunta et al.: The immunology of traumatic brain injury: a prime target for Alzheimer's disease prevention. Journal of Neuroinflammation 2012 9:185.

\section{Submit your next manuscript to BioMed Central and take full advantage of:}

- Convenient online submission

- Thorough peer review

- No space constraints or color figure charges

- Immediate publication on acceptance

- Inclusion in PubMed, CAS, Scopus and Google Scholar

- Research which is freely available for redistribution 